\section{Commentary: When spontaneous means threatening. The importance of thinking differently to prevent an unexpected, severe event}

\author{
Mohsen Ibrahim, MD, PhD, and \\ Beatrice Trabalza Marinucci, MD
}

The potentially serious complication of lobar torsion following pulmonary resection surgery is well known. Lobar torsion is defined as a parenchyma rotation on its bronchovascular pedicle that results in airway obstruction and vascular compromise. It may influence a single lobe or the entire lung. The true incidence of lobar torsion after pulmonary resection is difficult to determine. Keagy and colleagues ${ }^{1}$ noted an incidence of $0.3 \%$, Larsson and colleagues ${ }^{2}$ described 4 cases in approximately 2000 thoracotomies (an incidence of $0.2 \%$ ), and Cable and colleagues ${ }^{3}$ reported an incidence of $0.089 \%$.

Many surgical procedures have been described to prevent this rare and possibly life-threatening complication. In accord with Wagner and Nesbitt, middle lobar torsion after right upper lobe resections is the most frequent, accounting for $70 \%$ of the cases in the literature, whereas nearly $15 \%$ follow resection of the left upper lobe. ${ }^{4}$

The correct position of the remaining lobes should be confirmed cautiously. Then, fixation should be performed if little or no parenchymal bridge exists between contiguous lobes. Several techniques are described, including 1 where the edges of the middle and lower lobes are grasped with

\footnotetext{
From the Department of Medical-Surgical Science and Translational Medicine, Sapienza University of Rome, and Department of Thoracic Surgery, Sant'Andrea Hospital, Rome, Italy.

Disclosures: The authors reported no conflicts of interest.

The Journal policy requires editors and reviewers to disclose conflicts of interest and to decline handling or reviewing manuscripts for which they may have a conflict of interest. The editors and reviewers of this article have no conflicts of interest.

Received for publication Feb 1, 2021; revisions received Feb 1, 2021; accepted for publication Feb 3, 2021; available ahead of print Feb 7, 2021.

Address for reprints: Mohsen Ibrahim, MD, PhD, Department of Thoracic Surgery,

Sant'Andrea Hospital, Via di Grottarossa 1035, 00189 Rome, Italy (E-mail:

mohesen.ibrahim@uniroma1.it).

JTCVS Techniques 2021;7:305-6

2666-2507

Copyright (C) 2021 The Authors. Published by Elsevier Inc. on behalf of The American Association for Thoracic Surgery. This is an open access article under the CC BY-NCND license (http://creativecommons.org/licenses/by-nc-nd/4.0/).

https://doi.org/10.1016/j.xjtc.2021.02.007
}

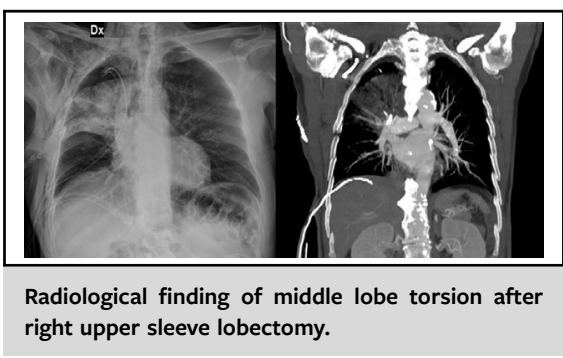

CENTRAL MESSAGE

A prompt diagnosis of a rare, lifethreatening event could allow a parenchymal-sparing surgical treatment.

a clamp and approximated along the course of the fissure, then sutured with a silk tie or stapled with an unsupported or reinforced Endo Gia universal stapler (Medtronic, Minneapolis, Minn) or Covidien TA 30 stapler. $^{5}$

Classic interlobular suturing is generally effective to adhere the lobes, but this could result in postoperative air leak, hemorrhage, and torsion due to detachment or laceration of both lobes. For this reason, several innovative techniques for preventing air leakage consist of synthetic polymers (eg, BioGlue [Cryolife Inc, Kennesaw, Ga] or Coseal [Baxter, Deerfield, Ill]) or pleural flaps. ${ }^{6-8}$ These techniques are generally applied for patients with emphysema, in whom sealant use is considered safer.

Nevertheless, spontaneous lobar and lung torsion are rare events. Ohde and colleagues ${ }^{9}$ wrote that approximately 10 cases of spontaneous pulmonary torsion have been reported in literature to date, and a few other experiences were added later. ${ }^{10,11}$ So, the frequency of these spontaneous event is difficult to assess. A prompt diagnosis is extremely important for conservative management, allowing a surgical lungsparing procedure before the parenchyma is compromised by gangrene or ischemia. Unfortunately, spontaneous lobar torsion can derive from several unexpected causes, including anatomic variability of vessels, lack of an inferior pulmonary ligament, or pleural space expansion. Considering any possible pathogenesis, the timing of ischemic injury and parenchymal damage are not predictable and conservative surgical treatment seems not always to be possible. In fact, torsion could produce infarction, ischemia, or hemorrhagic engorgement and in these cases, lobectomy would be necessary.

This interesting experience of spontaneous bilobar torsion $^{12}$ highlights the extreme importance of different 
thinking because surgeons have to consider all the possibilities to promptly detect a spontaneous, and potentially lifethreatening event. As Albert Einstein once said, thinking differently is important because "everybody knows a certain thing is unrealizable until somebody unaware of this comes and invents it." In front of an unexpected event, making a rare but possible diagnosis could save a lobe and a life!

\section{References}

1. Keagy BA, Lores ME, Starek PJK. Elective pulmonary lobectomy: factors associated with morbidity and operative mortality. Ann Thorac Surg. 1985;40:349-52.

2. Larsson S, Lepore V, Dernevik L, Nilsson F, Selin K. Torsion of a lung lobe: diagnosis and treatment. Thorac Cardiovasc Surg. 1988;36:281-3.

3. Cable DG, Deschamps C, Allen MS, Miller DL, Nichols FC, Trastek VF, et al. Lobar torsion after pulmonary resection: presentation and outcome. J Thorac Cardiovasc Surg. 2001;122:1091-3.

4. Wagner RB, Nesbitt JC. Pulmonary torsion and gangrene. Chest Surg Clin North Am. 1992;2:839-52.
5. Venuta F, Anile M, de Giacomo T, Coloni GF. Prevention of middle lobe torsion after right upper lobectomy with a polymeric sealant. J Thorac Cardiovasc Surg. 2012;143:240-1.

6. Woong PS, Goldstraw P. Pulmonary torsion: a questionnaire survey and a survey of the literature. Ann Thorac Surg. 1992;54:286-8.

7. Irie M, Okumara N, Nakano J, Fujiwara A, Noguchi M, Kayawake H, et al. Spontaneous whole-lung torsion after massive pleural effusion and atelectasis. Ann Thorac Surg. 2014;97:329-32.

8. Kutlu CA, Olgac G. Pleural flap to prevent lobar torsion: a novel technique. Eur J Cardiothorac Surg. 2006;30:943-4.

9. Ohde Y, Nakagawa K, Okumura T, Kondo H. Spontaneous pulmonary torsion secondary to pseudo-Meigs' syndrome. Interact Cardiovasc Thorac Surg. 2005;4:59-60.

10. Raynaud C, Lenoir S, Caliandro R, Raffenne L, Validire P, Gossot D. Spontaneous middle lobe torsion secondary to pleural effusion. Chest. 2009;136:281-3.

11. Ekstein SF, McCambridge A, Edell ES, Koo CW, Blackmon SH. Case of spontaneous whole-lung torsion with literature review. J Thorac Dis. 2018; 10:E690-3.

12. Qaqish TR, Chainani A, Batchelor E, Thanawala R, Jonsdottir H, Krishnan S, et al. Spontaneous bilobar torsion managed with pneumopexy. J Thorac Cardiovasc Surg Tech. 2021;7:301-4. 